\title{
An Analysis of an Intensive English for Academic Purposes’ (IEAP) Textbook: A Case Study of Pannasastra University of Cambodia (PUC)
}

\author{
Bunhorn Doeur \\ Pannasastra University of Cambodia (PUC), Siem Reap, Cambodia
}

\begin{abstract}
In this study, the researcher uses document analysis to explore the contents of one textbook—New Interchange 1, which has been used in an intensive English for academic purposes (IEAP) programme at Pannasastra University of Cambodia in Siem Reap (PUC-SR). This analysis is aimed at exploring how communicative the textbook is in nature. To do this, the contents/texts in the textbook are analysed and grouped into 10 categories, namely: (1) ask and answer dialogue; (2) situational dialogue; (3) communicative dialogue; (4) information-gap activity; (5) opinion-sharing activity; (6) reasoning-gap activity; (7) learner autonomy; (8) focus on meaning; (9) thinking skill; and (10) focus on form. Results show that the textbook prioritises "information-gap activity" and "opinion-sharing activity” followed by "ask and answer dialogue” and "situational dialogue.” In stark contrast, "learner autonomy” and "thinking skill” appear least frequently in this beginner textbook. However, the textbook is generally seen to be high-communicative in nature, because mixed tasks/activities are used throughout the textbook, so that students can be exposed to a wide range of communicative activities. Moreover, these tasks/activities are claimed to be communicative task types in the literature.
\end{abstract}

Keywords: intensive English for academic purposes (IEAP), New Interchange, communicative language teaching (CLT)

\section{Introduction}

This study explores the existing document, that is, a textbook of one English programme called intensive English for academic purposes (IEAP) at a private university in Cambodia. This textbook is being analysed within a framework of one teaching methodology that reported in the literature review section-communicative language teaching (CLT). Through an analysis of the textbook, findings will indicate how each activity or lesson throughout the textbook aligns with existing principles of CLT, and how communicative the whole textbook is in nature if compared to some principles of CLT informed in the literature. Through the process of the analysis of the textbook-A Revising Curriculum, particularly teaching outline of the prescribed textbook, would be made with some suggested additional materials for effective communication in addition to those activities designed in the textbooks - if not any/enough. Moreover, the findings will suggest an evaluation for continuous professional development for teachers of IEAP in order to train/inform the contemporary CLT practices within the region and the world today.

Bunhorn Doeur, M.A., lecturer, Faculty of Education, Pannasastra University of Cambodia (PUC). 


\section{Brief Background of Cambodian Universities}

The Royal University of Law and Economics (RULE) was built in 1949, which as the National Institute of Law, Politics, and Economic Sciences, was the first Cambodian Higher Education Institution (HEIs) (Mak, 2005). French was the only language of instruction at that time (Chamnan \& Ford, 2004). Not long after that, his Majesty King Norodom Sihanouk turned his attention to the development of education, so he allocated more than $20 \%$ of the annual national expenditure on the improvement of education (Ayres, 2000, as cited in Leng, 2010). According to Mak (2005), the Khmer Royal University (now known as the Royal University of Phnom Penh [RUPP]) which was opened in 1960, was the first Cambodian public university, and higher education during this period grew significantly. Nine HEIs were opened in Phnom Penh and other important provinces during the 1960s (Chamnan \& Ford, 2004).

In the 1970s, the development of higher education was neglected because of civil wars, general Lon Nol's military coup (1970-1975) and Pol Pot regime (1975-1978) known as "killing fields." Schools and universities were closed, and around $75 \%$ of university lecturers and $96 \%$ of university students were killed at this time (Chamnan \& Ford, 2004). On January 7, 1979, Vietnamese soldiers invaded Cambodia and helped create the People's Republic of Kampuchea (PRK) and led the country.

Four major political factions signed the Paris Peace Accord on October 23, 1991, and led to a general election in 1993, organised by the United Nations (UN) (Neau, 2010). Since then, Cambodian students can attend English and French classes, and now English is the most prominent foreign language in Cambodia (Neau, 2010). Because public HEIs were not widely accessible in the late 1990s, the Royal Government established a policy of privatization in higher education, and in 1997, Norton University was licensed to operate (Mak, 2005). Both private and public universities have been mushrooming across the country. There are currently 101 HEIs nationwide, and the total number of students being enrolled in Bachelor's degrees in the academic year 2011-2012 was 207,666 (MoEYS, 2013).

\section{The Teaching and Learning English at Cambodian Universities}

English has become increasingly popular in Cambodia, and being able to use it as a requirement for many jobs in Cambodia. Seeing this social phenomenon, many students have become interested in learning English, which is regarded as a foreign language in all academic programmes at tertiary level (MoEYS, 2007). Joseph A. Mussomeli (2017), the American ambassador to Cambodia, said at an international conference of English language teachers-Cambodian teaching English to speakers of other languages (CamTESOL) - in Phnom Penh that teaching English to Cambodian students was providing them with useful life skills, so that they can bring prosperity to their country, and that English is a tool or a "weapon" which enables us to reduce poverty and eliminate ignorance in Cambodia and to communicate with others in the world (Igawa \& Tsujioka, 2009).

Therefore, high school graduates become more interested in learning English as their foreign language. At the same time, language training schools and universities offer an increasing variety of English training courses for the market demands. In order to gain popularity and effectiveness in teaching, individual institutions continuously seek to improve their teaching methods and approaches. As the field of teaching English has been rapidly growing as described above, the learners of English become interested in becoming English language teachers. As a result, the number of enrolees in Bachelor of Arts (B.A.) in English, Bachelor of Education 
(B.Ed.) in teaching English as a foreign language (TEFL), or B.A. in TESOL programmes in the academic year 2008-2009 was 4,163 students (MoEYS, 2013).

\section{Background of and Programmes at PUC-SR}

Pannasastra University of Cambodia in Siem Reap (PUC-SR), the youngest campus, is one of PUC campuses in Cambodia, which is similar to other campuses in Phnom Penh. PUC-SR offers language training and undergraduate and graduate programmes of various disciplines. In language training, PUC-SR runs three main programmes of English, namely, IEAP, general English as a second language (GESL), and English for high school students (EHSS), to prepare learners for either undergraduate or graduate endeavour, the medium of language instruction of the programmes is English. In these language programmes, IEAP operates full-time - three hours per day, Monday to Friday and for 12-week per term, whereas GESL and EHSS are part-time programmes — one and a half hours per day and Monday to Friday, within a 12-week term.

In regards to full-time IEAP programme in detail at PUS-SR, there are five levels, namely, beginner and level 1 up to level 4 (see http://www.sr.puc.edu.kh). In every level, there are two teachers, who teach for one hour and a half each. New Interchange is the primary textbook series throughout the five levels whereas other textbooks are not used for every level of IEAP. The textbooks, which are used at PUC-SR, include: (a) New Interchange Introduction and Side by Side for beginner level; (b) New Interchange 1, Listen to Me and Facts \& Figures for level 1; (c) New Interchange 1 \& 2, In the Real World and Thoughts \& Notions for level 2; (d) New Interchange 2 \& 3, First Steps in Academic Writing and Cause \& Effect for level 3; and (e) New Interchange 3 and Introduction to Academic Writing for level 4.

In addition to the prescribed textbooks, PUC-SR has employed teachers, whose first degree is necessarily in TESOL/TEFL. Some of the teachers have graduated/pursued their master's degree either in English language teaching discipline or in other fields of their own interests. However, all relevant teaching policies and teaching syllabi/outlines are centrally set and designed ready for teachers in advance.

\section{Current Research Into CLT in EFL Context}

In an era of globalization, an idea of "ideal native speaker" has been on a rapid decline. English language tends to serve the purpose of non-native English speakers who outnumber native speakers now. Since its inception, the proponents of CLT have been growing to prove its efficacy in ELT. Although the matter is mostly favoured with applying the CLT approach in an EFL classroom, some criticism has been laid against. For the most part, which is justified when evaluating its implementation in such countries as Korea, China, Japan, Bangladesh, and Vietnam where EFL teaching faced a lot of problems caused by local conditions. Chowdhry (2010) wrote "when CLT was introduced, the EFL context in which it would inevitably be applied was not considered.” As Ramanathan (1999, p. 212) also asserted the much professed and popular theories (i.e., CLT) devised in the inner-circle of countries may or may not be compatible with the teaching conditions in the outer-circle countries. This westernised methodology of ELT was alien to the locally sanctioned teacher-centred system where the authority of the teacher has local and cultural approval. Although teaching should never be stagnant, a paradigmatic shift in teaching methodology can cause a total collapse in language teaching. English as a second language (ESL)/English as a foreign language (EFL) necessarily take a cross-national and multi-cultural aspect, which has to consider local needs and socio-economic circumstances. 
Researchers and other stakeholders are keen to know its efficacy in Southeast Asian countries. Writing in a Chinese context, Wei (2011) wrote,

Given the gap between the theories of communicative competence and the task confronting EFL teaching and learning, most of the previous research studies maintained that EFL countries should carefully study their English teaching situations and decide how CLT can best serve their needs and interests.

A study conducted in Vietnam identified class size, grammar-based examinations, and the instructors' lack of exposure to authentic language as constraints on using CLT. Another study on English teachers' perceived difficulties in adopting CLT in South Korea suggested that EFL countries, like South Korea, need to change their fundamental approach to education before CLT can be adopted, because the predominance of text-centred and grammar-centred practices in Korea does not provide a basis for the student-centred, fluency-focused, and problem-solving activities required by CLT (Li, 1998, p. 66, as mentioned in Wei, 2011). Vasilopoulos (2008) wrote that,

Many years have passed since the introduction of CLT approach in Korea. However, despite curriculum reform and passage of time, many remain sceptical of the effectiveness of communicative methodology in the Korean English language classroom.

In China too, where the call for adoption of CLT was not accidental, it came from the educational problem that needed to be solved. This problem was the existing unsatisfactory teaching results of the traditional grammar-oriented method (Liao, 2000). The introduction of the CLT approach faced many hurdles in the Chinese context, as Liao quoted in Hird (1995) saying that,

The teachers believed that it was not feasible to adopt CLT, because China had its special characteristics. These characteristics included the teachers' inability to teach communicatively and grammar-focused examination pressure....

The government's educational policies and a special focus on increasing the students' communicative competence paved the way for the CLT approach in China. Wenjie (2009) referred to Hu (2005, p. 637) who said that,

Despite a lack of consensus among researchers regarding the appropriateness of CLT for China, the Ministry of Education was impressed by the high profile that the methodology enjoyed internationally, and was convinced that it would provide the best solution for the wide spread problem of students' low competence in using English for communication even after years of formal instruction in the language.

Akram and Mehmood (2011, p. 175) reported an experimental study conducted to know the importance of introducing the communicative approach in ELT in teacher training programs in Pakistan. They wrote,

CLT enhances the learners' confidence and it gives a sense of satisfaction to the teacher as well in the sense that he/she is successful in making the students use the foreign language in their conversation. CLT gives clarity to the expression.... Communicative approach is better than all the other methods of language teaching in general.

The review of related literature on CLT provides ample proof of its usefulness in English language teaching, despite the fact that some problems still persist. Here, a need arises to evaluate the feasibility of applying a communicative approach in those non-native countries where traditional methodology is still being used in ELT.

A more recent approach to CLT is seen as task-based language learning (TBLL), also known as task-based language teaching (TBLT), which focuses on the use of authentic language and on asking students to do 
meaningful tasks using the target language. Such tasks can include conducting an interview, visiting a doctor, or calling customer service for help. Assessment is primarily based on task outcome (the appropriate completion of real world tasks) rather than on accuracy of prescribed language forms. This makes TBLL popular for developing target language fluency and student confidence. As such TBLL can be considered a branch of CLT.

Prabhu (1987) popularised TBLL while working in Bangalore and India. Prabhu (1987) noticed that his students could learn language easily with a non-linguistic problem as when they were concentrating on linguistic questions. Other major scholars who had done research in this area are as follows. Ellis (2000) studied on two different theoretical frameworks of TBLL, and their relevance for language pedagogy. The two accounts were psycho-linguistic perspective and socio-cultural theory, and Ellis (2000) concluded psycholinguistic approach provided important information for planning task-based teaching and learning, whereas the socio-cultural approach illuminated the kinds of improvisation that teachers and learners needed to engage within a task-based activity to promote communicative efficiency and L2 acquisition.

Prior to Ellis's (2000) study, Tong (1999) argued that TBLL methodology should adopt a systematic learning approach (i.e., tasks should be graded and sequenced to provide a more systematic and ordered learning experience). More recently, Lai, Zhao, and Wang (2011) revealed that students reacted positively to the online TBLL experience, and produced good learning outcomes. Likewise, Carreres and Noriega-Sanchez (2011) agreed that while there had been many valuable contributions in translator training in recent years, a task-based approach was regarded as particularly relevant to translation pedagogy in the context of language learning. Moreover, a TBLL method provides an inclusive and flexible framework that allows enough for the integration of a variety of techniques and learning strategies (Carreres \& Noriega-Sanchez, 2011).

Most recent trend to CLT, applied linguists have stressed the central importance of inter-culture with an interest in the inter-face among language learning, thought, and social interaction. Inter-culture is considered as a dynamic process by which people not only draw on, but also use the resources and processes of cultures. Moreover, they may become familiar with those they may not be associated with in their interactions with others (Young \& Sercombe, 2010). An inter-cultural approach is absolutely central to influential curricular frameworks for language. The linguistic and cultural competences in respect to each language used by the learner are modified by knowledge of the other and contribution towards intercultural awareness, skills, and know-how through effective communication.

From this position, language learning is the best place within the educational field for the learning of and about cultures, reflecting powerful inter-relationships between language and cultures (Risager, 2006). The nature and salience of such associations are currently enjoying a resurgence of interest in applied linguistics (Kramsch, 2004). Addressing the teaching and learning of cultures particularly on English language programmes worldwide shows a growing body of literature exploring cultures, both as a context for and as an influence on English language teaching (ELT) and English language learner (ELL) (Young, Sachdev, \& Seedhouse, 2009). This literature included critiques of "culturally-loaded" classroom practices and broad curricular approaches to cultures, inter-culture, and language (e.g., Chu, Swaffar, \& Charney, 2002; Holliday, 1999; Hu, 2002). In contrast, a comparison of small body of work in the field has explored the "learning of and about cultures.” A large majority of the literature was purely theoretical or rhetorical in nature.

There were indications, in the studies of Holliday (1995) and Lazaraton (2003), a critical and mediating approach to cultures might be successful in motivating both learners and teachers. Such approaches attempt, to some extent, to destabilise views of cultures as discrete and exclusive entities that largely determine the actions 
of individuals, and to frame cultures in such a way that any social encounters can be cultural. They also aim to challenge stereotyping, that is, self-affirmation that depends upon the denigration of members of perceived outer groups (e.g., Holliday, 1999; Said, 1978), and to promote inter-culture as method as much as content.

The particular focus of Young and Sachdev's (2011) investigation was on the application of Byram's (1997) model of inter-cultural communicative competence (ICC). This model is unusual among the plethora of available models in pedagogical, and specifically applicable in formal language learning contexts, rather than simply modelling the act of inter-cultural communication (Chen, 2009). The ICC model foregrounds an evaluative-inter-cultural criticality within a cluster of factors for developing inter-cultural competence in learner-centre approach in foreign language education. In this conceptualisation, an inter-cultural approach promotes the "inter-cultural speaker" as a more attainable learner than the previously prevailing natives peaker. The inter-cultural speaker is defined as one who can effectively and appropriately mediate between world of origin and world of encountered difference. At the centre of this conceptualisation lies the belief that inter-cultural competence involves successfully mediating among cultures. The first culture or "C1," that an individual was acculturated into, and a second, or "C2," so that an individual aims to occupy a relativizing another culture or "C3." This aim bears a strong conceptual similarity to the thirdness discussed by Kramsch (1999), and the third space interrogated by the contributors to Kelly, Elliot, and Fant's (2001) exploration of inter-cultural communication and language learning in European higher education and others. Advocates argue this perspective that, in successfully effecting mediation among cultures, the likelihood of successful communication is enhanced.

Byram (1997) put a stress on an inextricable link between the ability to function effectively in a foreign language and the clusters of skills, knowledge, and attitudes. They can be acquired or changed, and which contribute towards inter-cultural competence. His ICC model attempts to build beginning models of inter-cultural competence and effectiveness in learner-centred, CLT (e.g., Van Ek, 1986; Van Ek \& Trim, 1991). He is also critical of lacking of emphasis on the inculcation of socio-cultural, as opposed to purely socio-linguistic, which he sees as inherent in these models. These have also been characterised as insufficient guidance to educators on how an inter-cultural approach to language learning can be operationalised in teaching and learning (e.g., Byram \& Risager, 1999).

Despite at least tangential support for an inter-cultural approach in a limited amount of work that addressed issues of culture and language learner effectiveness (Young et al., 2009), there had been very little empirical work on explorations of perceived applicability of this approach. It was this specific research gap that this exploratory study addressed.

According to S. Li and F. Li (2004), with ICC, ELT, and ELL were placed within a broad context of global inter-cultural communication in which learners were trained to cope with potential linguistic and non-linguistic problems. English is taught as an international language used for inter-cultural communication.

Moreover, a proposed inter-cultural framework goes beyond the learning and teaching of linguistic codes to a broader area of inter-cultural education where language is seen as essential for effective communication. The CLT, however, limits language teaching and learning to the study of language instead of locating it within a broader and more general context where communicative ability is regarded as contributing to the learners' generic competence. The term inter-culture in a proposed inter-cultural framework captures a close link between language and culture, while CLT only sees language as related to culture but not as culture, and thus, prevents teachers and learners from grasping the true nature and meaning of language learning. 


\section{Research Context}

For this study, the researcher has chosen only one private university in Siem Reap, Cambodia, and PUC-SR. This university is distinguished from many others in Cambodia for its strict admission and independent design of its chosen textbooks and independent curriculum. At the PUC-SR, students are required to pass the English placement test or successfully complete English training courses, one of the main programmes is IEAP, to be eligible in the academic programmes because all disciplines of both undergraduate and graduate are conducted in English (PUC, 2013).

\section{Document Selection}

In this study, the researcher surveys only one textbook - New Interchange 1-of four New Interchange Series, which have been using for the IEAP programme at the PUC-SR because the researcher finds that the four textbooks are very similar in patterns an/or structures of the whole book and in each unit. Other than that, the timeline of this dissertation is limited, which does allow the researcher to examine all of the textbooks. Generally, each book contains 16 units, and each unit consists of conversations, speaking, pronunciation, grammar focus, snapshot, word power, listening, interchange, and reading. The only difference is the order of those components from one unit to another throughout the textbook, and the level of difficulty from one book to another. Therefore, analysing one textbook-New Interchange 1-can represent the whole series of New Interchange, which are mainly authored by Richards, Hull, and Proctor (2005).

\section{Procedures}

The researcher obtained PDF copies of the textbooks from the PUC-SR management team back in Siem reap, Cambodia, so he printed out a copy of New Interchange 1 for analysis. Then, he listed the nine main characteristic principles of CLT with number 1 to 9 as following: (1) ask and answer dialogue; (2) situational dialogue; (3) communicative dialogue; (4) information-gap activities; (5) opinion-sharing activities; (6) reasoning-gap activities; (7) learner autonomy; (8) focus on meaning; and (9) thinking skills. The analysis started with numbers represented the chosen categories mentioned above to appropriate activity/instruction. Thus, those numbers were labelled to individual instruction/task.

However, after the analysis finished the whole textbook of New Interchange 1, there were some instructions/activities that fell out of the nine characteristics. Looking into those remaining items, three more characteristics were added to cover all of those items. They included: (10) focus on form; (11) pronunciation; and (12) self-assessment. The last two groups were used as their sub-headings in the textbook, because they did not match to any other principles of CLT found in the literature discussed above.

\section{Data Analysis}

Document analysis involves skimming, reading, and interpretation. This iterative process combines elements of content analysis and thematic analysis. Content analysis is the process of organising information into categories. Some qualitative research experts may object to content analysis, contending as Silverman (2000) did, that it obscured the interpretive processes that turned talk into text. It entails a first-pass document review, in which meaningful and relevant passages of text or other data are identified. The researcher should demonstrate the capacity to identify pertinent information and to separate it from that, which is not pertinent (Corbin \& Strauss, 2008; Strauss \& Corbin, 1998). 
Thematic analysis is a form of pattern recognition within the data, with emerging themes becoming the categories for analysis (Fereday \& Muir-Cochrane, 2006). The process involves a careful, more focused re-reading, and review of the data. The reviewer takes a closer look at the selected data and performs coding and category construction, based on the data's characteristics, to uncover themes pertinent to a phenomenon. Predefined codes may be used. Codes and the themes they generate serve to integrate data gathered by different methods.

For the present study, the researcher has set a framework comprising often characteristics of CLT discussed in the literature as themes. They are borrowed from Dornyei (2009), Jacobs and Farrell (2003), Jin (2012), and Richards (2006). Of the 10, one from Dornyei (2009) is "focus on form." He originally did not include "focus on form" in the analysis, but after analysing the whole textbook he realised that those grammar focuses, usually two per unit, with grammar explanations and form illustrations should be under one category of "focus on form."

In addition, three components-learner autonomy, focus on meaning, and thinking skills, suggested by Jacobs and Farrell (2003), were included in the analysis, because they found key principles of CLT. Within the analysis, every piece of instructions are taken into considerations in order to decide which category/theme of each activity is suitable based on its own definition or meaning.

Other three characteristics of Jin (2012) included "ask and answer dialogue," "situational dialogue," and "communicative dialogue” were also employed. The only instructions/tasks for "ask and answer dialogue” were those of "listen and practice" throughout the textbook, because students had to ask and answer what in the dialogue were. Other dialogues that students had to practice and add or continue using students' initiatives were considered as "situational dialogue." In addition, when students had to work interactively in pairs or groups, those were categorised into "communicative dialogue." For example, in a group work in the discussion on page 32, students had to ask their classmates about family members, and they had to ask follow up questions where necessary. By doing this, students became more independent in their communication.

Last three categories, information-gap activities, opinion-sharing activities, and reasoning-gap activities suggested by Richards (2006) were also included in the framework. Very simple instructions, which were categorised into information-gap activities, were "complete these sentences," "complete these questions," "complete these conversations," "listen to the conversations and complete the information about each person," "check the statements that are true based on the reading passage," "complete the word map with words from the list," and so on. However, opinion-sharing activities usually followed other activities in general, which require students to check their answers, share ideas, or discuss on given topics, in a form of pair work or group work. The last component from Richards (2006) was reasoning-gap activities. Similar to information-gap, reasoning-gap requires students to complete the gap or answer some questions, but more independently with reasons to the choice being made. For example, "Would you like to try any of these sports? Why or why not?” (p. 69).

\section{Scope and Limitations}

In relation to other qualitative research methods, document analysis has both advantages and limitations. Those advantages are as followings: (a) efficient method-less time-consuming and more efficient than other research methods. It requires data selection, instead of data collection; (b) availability —many documents are in the public domain, especially since the advent of the Internet, and are obtainable without the authors' 
permission; (c) cost-effectiveness-less cost than other research methods; (d) lack of obtrusiveness and reactivity, unobtrusive, and non-reactive — unaffected by the research process; (e) stability—being non-reactive, documents are stable; (f) exactness - inclusion of exact names, references, and details of events makes documents advantageous in the research process (Yin, 2003); and (g) coverage—broad coverage of a long span of time, many events, and many settings (Yin, 2003).

However, document analysis still contains a number of limitations as described below. Firstly, insufficient detail: Documents are produced for some purpose other than research; and they are created independent of a research agenda. Consequently, they usually do not provide sufficient detail to answer a research question. Fortunately, the research question in this study was narrowed down in the hope that there was no much gap in the analysis. Nevertheless, limitation still existed it was not always accurate deciding an instruction/task into the group. Another limitation is low retrievability: Documentation is sometimes not retrievable, or retrievability is difficult. As Yin (2003) had noted, access to documents might be deliberately blocked, but this was not a case in this study, because the management team of the selected university was satisfied. Last but not least, biased selectivity: An incomplete collection of documents suggests "biased selectivity" (Yin, 2003, p. 80). In this study, selection bias might be choosing only one textbook for an analysis because of the timeline of the dissertation. Given its efficiency and cost-effectiveness in particular, document analysis offers advantages that clearly outweigh the limitations. Hence, the researcher employed this method for analysing such data obtaining-New Interchange 1, within the framework of communicative language teaching.

\section{Results and Discussion}

This chapter presents the findings and discussion from the analysis of the textbook — New Interchange 1. The textbook is analysed to explore how communicative it is in nature. By using some principles of communicative language teaching in this analysis, results are reporting below. Following the results, discussion on each characteristic of CLT principles, which are shown in the textbook, is comprehensively provided.

\section{Results}

The findings using 10 major characteristics that deem to indicate use of CLT approach to classroom activities suggested by Dornyei (2009), Jacobs and Farrell (2003), Jin (2012), and Richards (2006) as discussed in the literature above. These categories included: (1) ask and answer dialogue; (2) situational dialogue; (3) communicative dialogue; (4) information-gap activities; (5) opinion-sharing activities; (6) reasoning-gap activities; (7) learner autonomy; (8) focus on meaning; (9) thinking skills; and (10) focus on form. However, some activities in the book cannot be categorised into the 10 groups, and therefore, they are categorised according to their sub-headings in the textbook, which include "pronunciation" and "self-assessment."

According to Table 1, the most frequent activities throughout the textbook are "information-gap activities" and "opinion-sharing activities," which appear in the textbook for 17\% and 15\% of activities respectively. On the contrary, besides those, which do not fall into the ten categories, "reasoning-gap activities" and "thinking skills" are designed least frequently in the textbook-New Interchange 1, with $5 \%$ and $6 \%$ respectively. The other six categories appear between $8 \%$ and $11 \%$ of the time. However, the two categories, which are out of the ten characteristics selected-“pronunciation" and "self-assessment," appear $1 \%$ and $2 \%$ of the time respectively. 
Table 1

Frequency of Types of Tasks

\begin{tabular}{lcc}
\hline Activities & Frequency & Percent (\%) \\
\hline Ask and answer dialogue & 56 & 11 \\
Situational dialogue & 54 & 11 \\
Communicative dialogue & 41 & 8 \\
Information-gap activities & 85 & 17 \\
Opinion-sharing activities & 76 & 15 \\
Reasoning-gap activities & 27 & 5 \\
Learner autonomy & 40 & 8 \\
Focus on meaning & 40 & 8 \\
Thinking skills & 30 & 6 \\
Focus on form & 45 & 9 \\
Pronunciation & 3 & 1 \\
Self-assessment & 8 & 2 \\
Mean & 42 & 8 \\
Total & 505 & 100 \\
\hline
\end{tabular}

More specifically, looking into each category for more detail. Firstly, “ask and answer dialogue (11\%)," appears slightly above average, which is $8 \%$. This style of activity appears throughout the textbook and as Jin (2012) argued that this kind of activities could be acted between either students and students or students and teacher. This activity appears in the same task type and/or instruction pattern, which is "listen and practice," in a sub-heading of "conversation" within the unit. Below is an example task, which is categorised as "ask and answer dialogue" throughout the textbook in the analysis, extracted from the textbook’s Unit 7.

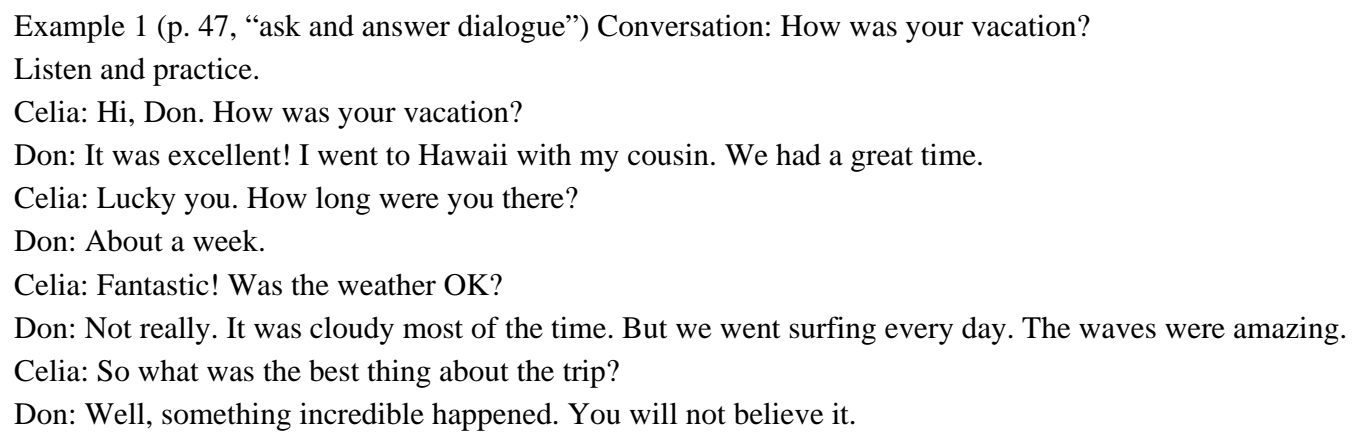

This activity is aimed at students to practice the model conversation within given functional situation, which builds foundation of communicative skills. This type of task usually precedes "situational conversation," where students have opportunities to communicate independently with their peers in a given topic. Later on, "grammar focus" is introduced explicitly in detail of what is presented in sample conversation. Therefore, within that simple practice of conversation, students are contextualised/exposed to the new language pattern in a communicative way, because students have already practiced the target language within context. To have better understanding of the task/activity, another example would be raised below.

Example 2 (p. 64, “ask and answer dialogue”) Conversation: A visit to New Orleans.

Listen and practice.

Jan: It is great to see you, Todd. Have you been in New Orleans long? 
Todd: Just a few days. I am really excited to be here.

Jan: I cannot wait to show you the city. Have you been to a jazz club yet?

Todd: Yeah, I have already been to one.

Jan: Oh. Well, how about a riverboat tour?

Todd: Uh, I have already done that, too.

Jan: Have you ridden in a streetcar? They are a lot of fun.

Todd: Actually, that is how I got here today.

Jan: Well, is there anything you want to do?

Todd: You know, I really just want to take it easy. My feet are killing me.

In this task, students are asked to practice the conversation in pairs. One acts as Jan and another partner plays a role as Todd. After that, students change their roles between Jan and Todd. By practicing this activity, students are exposed to present perfect with "already" and "yet." Therefore, meanings of those languages are given within context of the conversation.

Another characteristic task of CLT, which is included in the analysis, "situational dialogue" appears similar time to "ask and answer dialogue (11\%)." This meant that, students are not only given opportunities to practice the conversations as discussed above, but they also have chances to have their own conversations within given situations. As a result, they become independent communicators from one activity to another within a unit and/or throughout the textbook although they are in that low level-beginner. Additionally, "communicative dialogue" appears as the fifth most frequent type of communicative activity in the textbook with $8 \%$ of occurrences within the texts. This activity gives students more advanced works better communication skills where they produce language independently on given situations. An example of communicative dialogue is given below.

Example 3 (p. 18, “communicative dialogue”) Role Play: Can I help you?

Pair Work. Put items "for sale” on your desk or a table-notebooks, watches, or bags. Use items of different colours.

Student A: You are a clerk. Answer the customer's questions.

Student B: You are a customer. Ask about the price of each item. Say if you want to buy it.

A: Can I help you?

B: Yes. I like these sunglasses. How much are they?

A: Which ones?

Change roles and try the role play again.

This task type is similar to "situational dialogue" in a form of communication patterns. However, they are analysed based on the degree of independent in communication. "Communicative dialogue" is considered a higher level of communication than it is in the "situational dialogue." To have better understanding of how they are different, Example 4 and Example 5 of "situational dialogue" below are shown in addition to Example 3, which is a "communicative dialogue" task type.

Example 4 (p. 26, “situational dialogue”)

Writing A: Text message

\begin{tabular}{|c|c|c|c|c|c|}
\hline $\mathbf{M}=\mathrm{am}$ & $\mathrm{U}=\mathrm{you}$ & $\mathrm{R}=$ are & $\mathrm{C}=$ see & $4=$ for & $2=$ to \\
\hline L8 = late & W8 $=$ wait & GR8 = great & $\mathrm{THX}=$ thanks & LUV $=$ love & NITE $=$ night \\
\hline
\end{tabular}

B. Group work. Write a text message to each person in your group. Then exchange messages. Write a response to each message. 
Example 5 (p. 29) Speaking: What an excuse!

C. Group work. Shuffle the invitation cards together and the response cards together. Take three cards from each pile. Then invite people to do the things on your invitation cards. Use the response cards to accept or refuse.

These two examples show the "situational dialogue," because students are given a topic that is in a specific situation either writing (Example 4) or speaking (Example 5).

The most dominating activities, as shown in Table 1, within the analysed textbook fall into "information-gap activities" with $17 \%$ of the activities, and "opinion-sharing activities" with $15 \%$ of the time. These activities appear the most frequent and double the mean with $8 \%$ of the time. This shows that the textbook very much focuses on the two activities, "information-gap” and "opinion-sharing activities." The two activities appear in different sub-headings, which are different from other characteristics. They are seen in different sub-headings, where students have to complete the information-gaps and share within their pairs and groups. From Examples 6, 7, 8, 9, 10, and 11 below, "information-gap activities” are seen in sub-headings of word power, listening, reading, and grammar focus. This is a wide range of activity where information is required for the gaps. Those examples of "information-gap" and "opinion-sharing activities" are as follows:

Example 6 (p. 30, “information-gap”)

\section{1) WORD POWER Family}

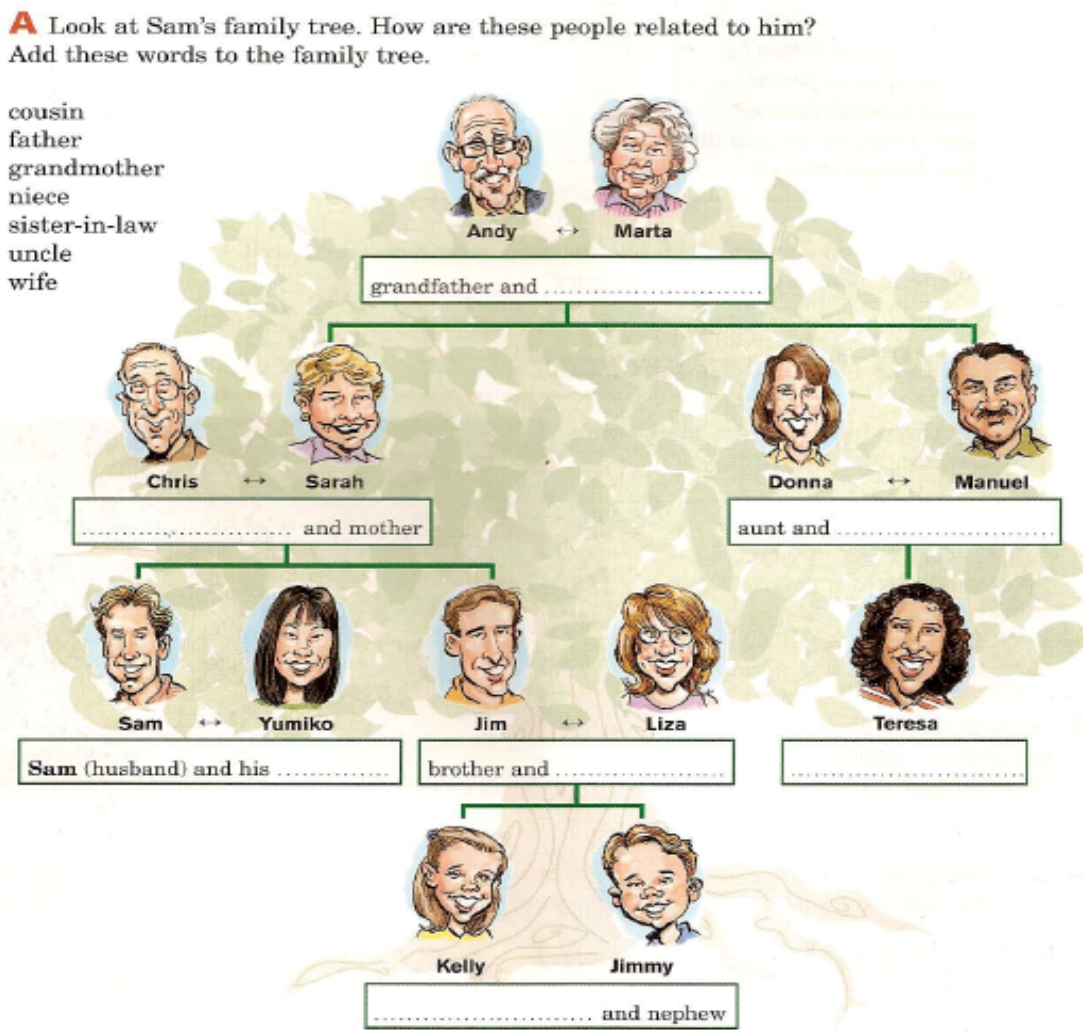

In Example 6, students are required to look at Sam's family tree and so they are able to identify those people and their relationship to Sam. As a result, they are able to fill in those blanks with words provided on the top left of the family tree. Although this activity focuses on vocabulary, the task designs for gap filling. Thus, this can be categorised as an "information-gap activities." 
Example 7 (p. 31, “information-gap”)

\section{LISTENING How are they related?}

(b) Listen to four conversations about famous people. How are the people related?
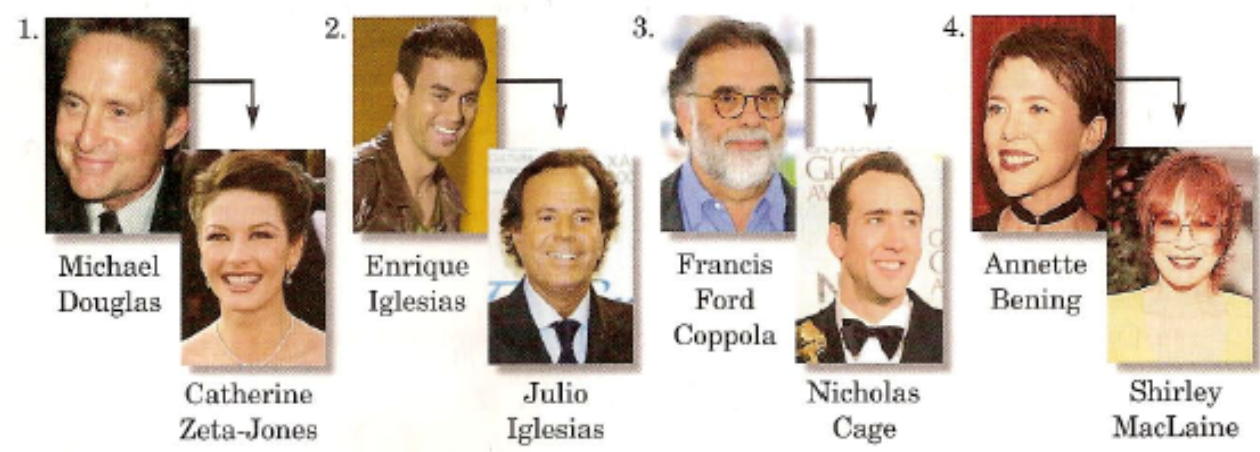

Example 7 again requires students to complete the gaps provided based on information they obtain from the listening. This activity shows "information-gap activities" in listening section.

Example 8 (p. 32, “information-gap” in Grammar Focus)

A Complete these phone conversations using the present continuous.

1

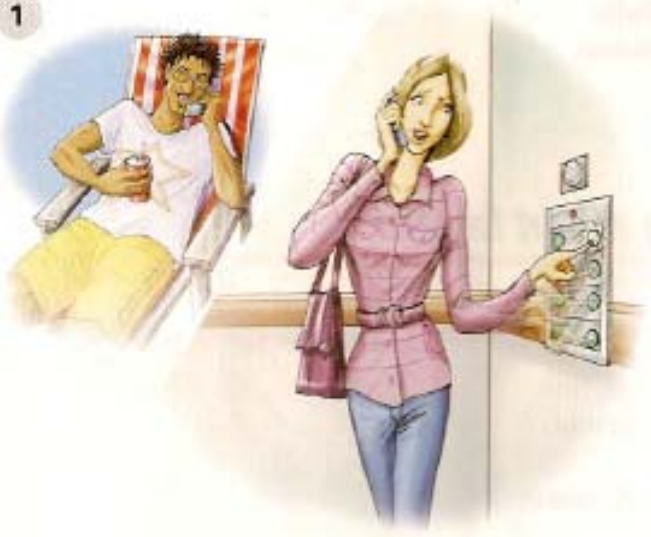

A: Hi, Stephanie. What (do)?

B: Hey, Mark. I elevator, and it's stuck!

A: Oh, no! Are you OK?

B: Yeah. I - wait! It Thank goodness!
2

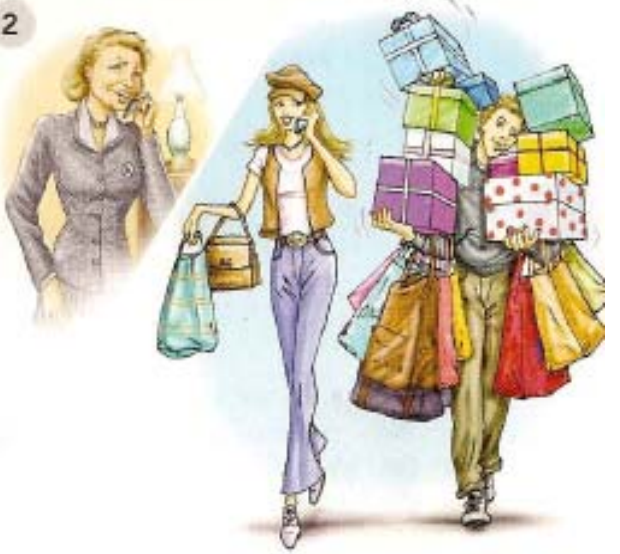

A: Marci, how ........... you and Justin (enjoy) your shopping trip?

B: We ............. (have) a lot of fun.

A . ........... your brother ........... (spend) a lot of money?

B: No, Mom. He ........... (buy) only one or two things. That's all!

In Example 8, students need to complete the gaps by using a grammar form, present continuous. This is a grammar exercise in practice where students practice the structure of present continuous tense for accuracy. However, it categorises as "information-gap activities," because again the task requires students to fill in those gaps. 
Example 9 (p. 34, first instruction is “information-gap” and second one is “opinion-sharing”) Grammar Focus

A. Rewrite these sentences using quantifiers (all, nearly all, most, many, a lot of, some, not many, a few, few, and no one). Then compare with a partner.

1. In China, $50 \%$ of women get married by the age of 22 .

2. In Australia, $87 \%$ of married couples have children.

3. In the United States, $0 \%$ of the people vote before the age of 18.

4. Thirty-five percent of the people live alone.

5. Seventy-eight percent of American high school students have jobs.

In Example 9, however, there are two types of activities, because as the analysis is based on both tasks and instructions, there are two separate sets of instructions, which can be divided. The first part of instruction requires students to rewrite the provided sentences or fill in the gaps using given quantifiers. Hence, it is "information-gap activities." In addition, the second part needs students to compare their own answers with a partner, where students share their ideas on what they have completed/done. This categorises as "opinion-sharing activities.” These two activities are in the sub-heading of grammar focus.

Example 10 (p. 35, “information-gap”) Reading: The Changing Family.

A. Read the article. Then, answer these questions. Write the names of the family members.

1. Which children are benefiting from Judy working?

2. Which child is not benefiting from Judy work?

3. Which family member is enjoying more freedom?

4. Which family members are doing more housework?

5. Which family member feels too busy?

Although the task in Example 10 appears in a reading section, it is an "information-gap activity," because students need to fill in the gap to answer the questions. This information is from the reading passage.

Example 11 (p. 36, first instruction in A is “information-gap” and second one is "opinion-sharing”)

\section{WORD POWER Sports and exercise}

A Which of these activities are popular with the following age groups? Check $(\checkmark)$ the activities. Then compare with a partner.

\begin{tabular}{|c|c|c|c|c|c|}
\hline & Children & Teens & $\begin{array}{l}\text { Young } \\
\text { adults } \\
\end{array}$ & $\begin{array}{l}\text { Midale-aged } \\
\text { people }\end{array}$ & $\begin{array}{l}\text { Older } \\
\text { people }\end{array}$ \\
\hline aerobics & $\Pi$ & $\square$ & 口 & $\square$ & $\square$ \\
\hline baseball & $\Pi$ & $\square$ & $\Pi$ & $\Pi$ & $\square$ \\
\hline bicycling & $\Pi$ & $\Pi$ & $\Pi$ & $\square$ & 口 \\
\hline in-line skating & $\Pi$ & $\square$ & $\Pi$ & $\sqcap$ & П \\
\hline soccer & $\Pi$ & $\square$ & $\Pi$ & $\Pi$ & $\Pi$ \\
\hline swimming & $\Pi$ & $\Pi$ & $n$ & $\Pi$ & $\Pi$ \\
\hline tennis & $\square$ & $\Pi$ & $\Pi$ & $\Pi$ & $\square$ \\
\hline weight training & $\Pi$ & $\Pi$ & $n$ & 11 & 11 \\
\hline yoga & $\pi$ & $\Pi$ & 几 & 川 & $\square$ \\
\hline
\end{tabular}

In contrast to Example 6, "information-gap activity" only, Example 11 in word power sub-heading contains not only "information-gap," but also "opinion-sharing activity.” This task is the same as Example 9, which consists of two parts of instructions. The first part requires students to check the activities provided, 
which they think are appropriate to different age groups of people— “information-gap activity.” Moreover, their individual answers need to be shared with a partner- “opinion-sharing."

Example 12 (p. 43, “opinion-sharing”) Survey: Family life.

B. Group work. Write up the results of the survey. Then tell the class.

1. In my group, most people are living with their family.

2. A few of their parents both work.

Example 12 is an "opinion-sharing activity," because students are required to work in groups and share their results within the groups from a survey, so that they can have their groups' results rather than their own. Even later, this groups' result is shared among other groups in the whole class.

"Reasoning-gap" and "thinking skills" have similar occurrences within the textbook with $5 \%$ and $6 \%$ of the time respectively. They are the lowest frequent activities among the 10 chosen characteristics of CLT within the textbook. These skills require more critical thinking on given topics. As the textbook is aimed at lower level beginner learners, reasoning, and critical thinking are not highly emphasised, because the main focus is given to basic and independent communicative skills. Below are examples given for both "reasoning-gap activities" and "thinking skills" that are quoted from the analysed textbook to have an idea of how the two activities are illustrated.

Example 13 (p. 25, “reasoning-gap” in exercise B)

\section{LISTENING Who's my date?}

A Listen to four people on a TV game show. Three men want to invite Linda on a date. What kinds of things do they like? What kinds of things does Linda like?

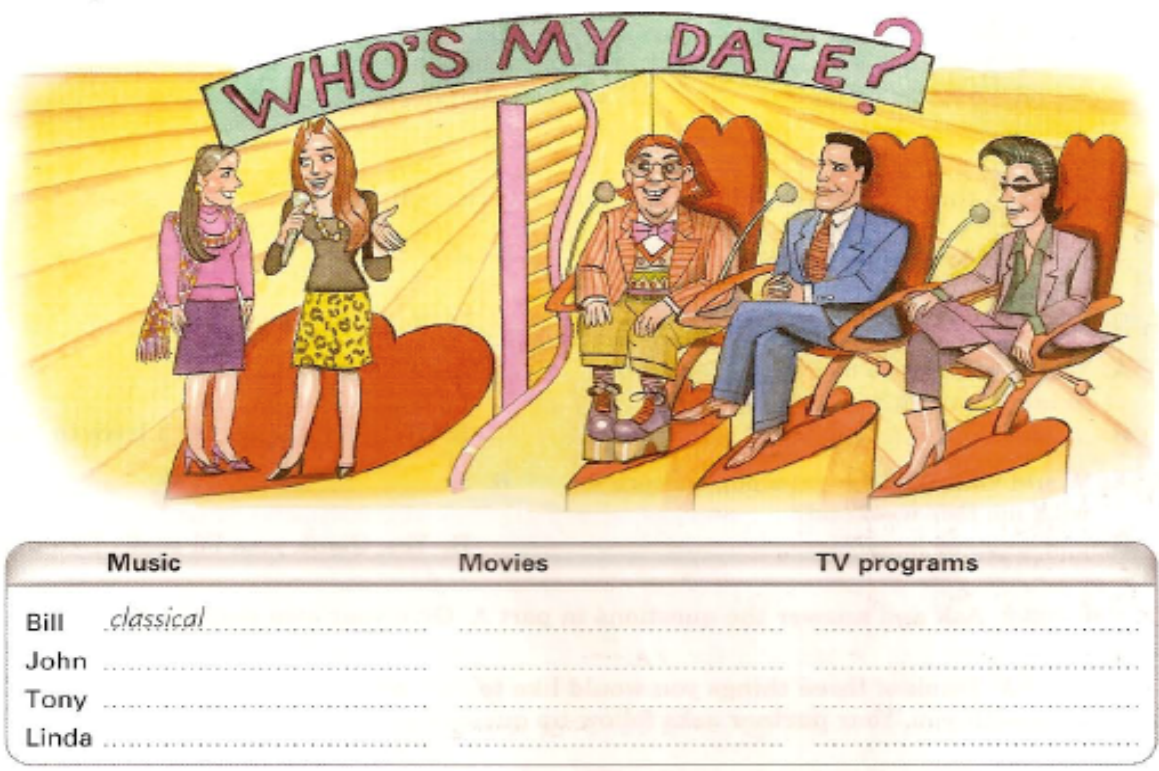

B Class activity Who do you think is the best date for Linda? Why?

In addition to Task A, in Task B or Example 13, students are required to choose the best date for Linda and they have to provide reasons for their thought according to the information-gap, in Task A that they already filled from listening. Task B is an example of "reasoning-gap activity." 
Example 14, (p. 13, “reasoning gap”) Reading.

B Pair work Choose the best job for each person. Explain why.

\begin{tabular}{|c|c|c|}
\hline Art Store Clerk & Grocery Store Cashier & Day-care Assistant \\
\hline $\begin{array}{l}9: 00 \text { A.M. to } 5: 00 \text { P.M. } \\
\$ 10 \text { an hour }\end{array}$ & $\begin{array}{l}\text { Flexible work hours } \\
\$ 5.50 \text { an hour }\end{array}$ & $\begin{array}{l}\text { Work with children } \\
\text { Earn great money }\end{array}$ \\
\hline Waiter/Waitress & Office Worker & Word Processor \\
\hline $\begin{array}{l}\text { Evenings only } \\
\text { Experience o plus }\end{array}$ & $\begin{array}{l}\text { Nights and evenings } \\
\text { No experience necessory }\end{array}$ & $\begin{array}{l}\text { Work at home } \\
\text { Earn up to } \$ 20 \text { on hour }\end{array}$ \\
\hline
\end{tabular}

This is a task in reading section where profiles of three people are provided, so that students are able to decide which job is appropriate for each of the three people. Although this task has no gap for students to fill in, they need to match between jobs and people with suitable reasons. Hence, this is an example (Example 14) of "reasoning-gap activity” either.

\section{Example 15 (p. 16, “thinking skills”)}

\section{SNAPSHOT}

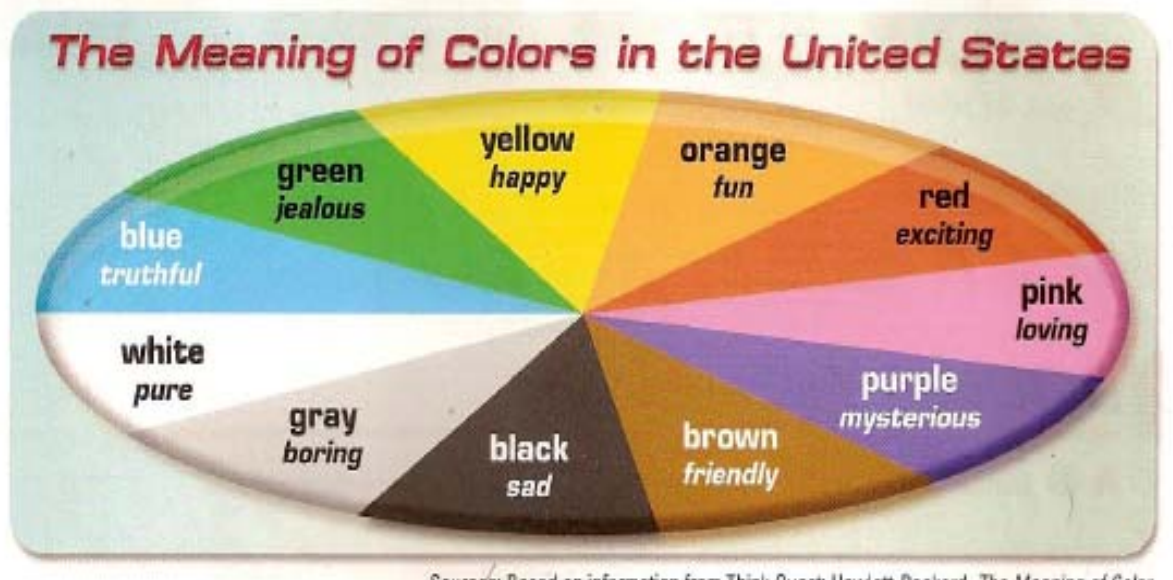

Sources: Based on information from Think Quest; Hewlett-Packard, The Meaning of Colar

Which words have a positive meaning? Which words have a negative meaning?

What meanings do these colors have for you?

What does your favorite color make you think of?

"Thinking skill activity" is shown in Example 15, which is the first task of the unit-Unit 3, as its sub-heading shows "Snapshot." In this task, instruction is not given. Instead there is a set of questions asking to the picture provided about meaning of colours in the United States. This task requires students to think critically or guess what the meaning of each colour is. To answer this type of task, students need comprehensively receptive skills. 
Example 16 (p. 22, “thinking skills”)

\section{SNAPSHOT}

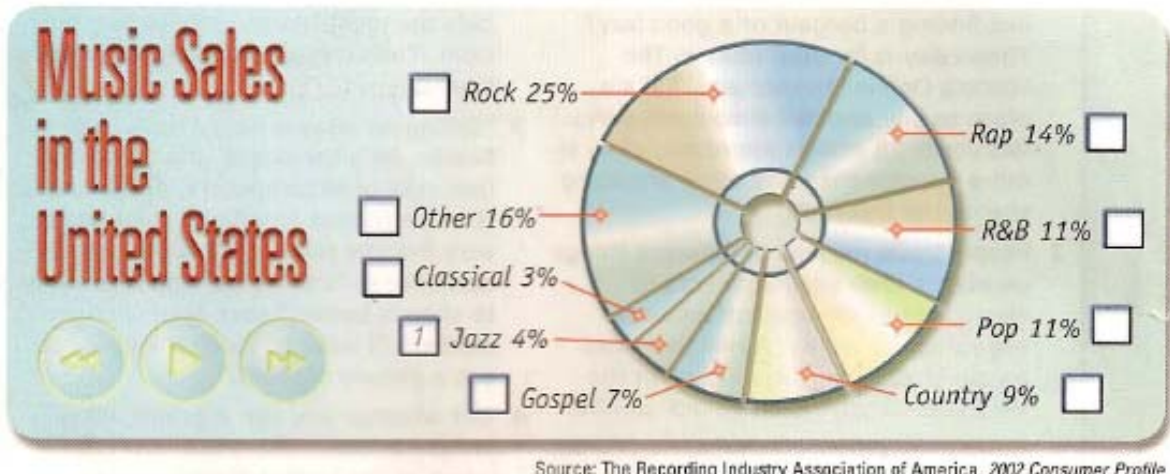

D) Listen and number the musical styles from 1 to 8 .

Which of these kinds of music are popular in your country?

What other kinds of music are popular in your country?

In addition to Example 15, "thinking skill” is also shown in Example 16. Again, the task appears in the same sub-heading- "Snapshot." However, it shows another different pattern of task type, in which the questions are drawn after a mini-listening task. This task requires students to be a higher level of critical thinking skills, because students have to compare the music sales in the United States and in Cambodia, where specific figures on sales are not available, but they compare based on their own experiences and observations.

Another common characteristic of activity in the textbook is "Focus on form" which appears $9 \%$ of the time. This form of activity is taken into consideration where a grammar point(s) is explained. Therefore, they all appear under the grammar focus sub-heading. Examples below are kinds of "focus on form activity," which is categorised within the analysis.

Example 17 (p. 59, “focus on form”)

\section{GRAMMAR FOCUS}

\section{Describing people 0}

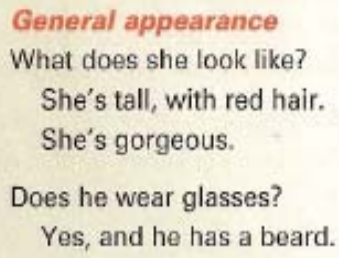

General appearance

What does she look like?

She's tall, with red hair.

She's gorgeous.

Does he wear glasses?

Yes, and he has a beard.

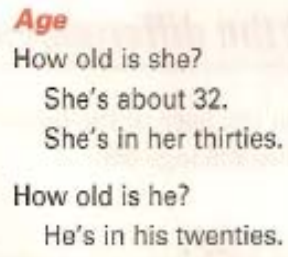

Age

How old is she?

She's about 32.

She's in her thirties.

How old is he? He's in his twenties.

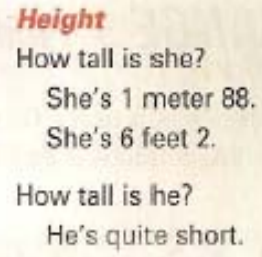

This task type of "focus on form" or "grammar focus" in the textbook is slightly differently from other types of task. This is no separate instruction to the illustration to the grammar point(s) itself. However, the focus of the explanation is on form(s) of grammar structures/rules. As an Example 17 shows, adjectives to describe appearances and how to form questions about general appearances, age, height, and hair are explained explicitly. 
Example 18 (p. 62, “focus on form”)

\section{GRAMMAR FOCUS}

\section{Modifiers with participles and prepositions $\mathrm{C}$}

\begin{tabular}{|c|c|c|}
\hline Who's Raoul? & He's the man & $\begin{array}{l}\text { Participles } \\
\text { wearing a green shirt. }\end{array}$ \\
\hline 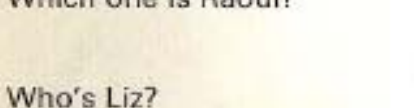 & 的 & $\begin{array}{l}\text { Preposi } \\
\text { with sho }\end{array}$ \\
\hline Which one is Julia? & all one & in jeans. \\
\hline Who are the Smiths? & They're the people & next to the \\
\hline Which ones are the Smiths? & They're the ones & on the couch. \\
\hline
\end{tabular}

Additional examples, Examples 18 and 19, are kinds of "focus on form," where Example 18 illustrates forms of modifiers with either participles or prepositions. Similarly, Example 19 presents present perfect with "already" and "yet." Again, these explain target languages as discussed explicitly. However, following reinforcements are usually followed as shown in Examples 8 and 9 above.

Example 19 (p. 65, “focus on form”)

\section{GRAMMAR FOCUS}

\section{Present perfect; already, yet 0}

The present perfect is formed with the verb have + the past participle.

Have you been to a jazz club? Yes, I've been to several. No, I haven't been to one.

Has she ridden in a streetcar? Yes, she's ridden in one. No, she hasn't ridden in one.

Has he called home lately? Yes, he's called twice this week. No, he hasn't called in months.

Have they eaten dinner yet? Yes, they've already eaten. No they haven't eaten yet.

Contractions

I've = I have he's = he has we've = we have haven't = have not

you've $=$ you have she's $=$ she has they've $=$ they have hasn't $=$ has not

it's = it has

For a complete list of irregular past participles, see the appendix at the back of the book.

Among the 10 characteristics, two activities are unique, because they had the same frequency although it is not high. Those activities are "learner autonomy" and "focus on meaning" and its frequency is $8 \%$ of the time. "Learner autonomy" refers to those activities which require students to do tasks on their own, while "focus on meaning” where students have to complete a specific task based on meanings. The two activities are illustrated with examples below.

Example 20 (p. 58, “learner autonomy”) Word Power: Appearance.

B. Pair Work. Choose at least four expressions to describe yourself and your partner. Then compare. Do you agree?

A: You have curly blond hair and a beard. You are young and good-looking.

B: I do not agree. My hair is not very curly. 
Example 21 (p. 60, “learner autonomy”) Writing: An e-mail describing people.

A. Imagine your e-pal is coming to visit you for the first time. You and a classmate are meeting him/her at the airport. Write an e-mail describing yourself and your classmate (Do not give the classmate’s name).

Examples 20 and 21 show a task type of "learner autonomy," because students are provided tasks that they need to achieve on their own or with their partners. This type of task provides a high level of independent work with less guidance/supervision from either teachers or clues.

Example 22 (p. 17, “focus on meaning”) Grammar Focus.

A. Write questions to match these statements.

1. My brother is 26 years old.

2. I am $173 \mathrm{~cm}$ (5 feet 8)

3. Sharon has brown hair.

4. No, she wears contact lenses.

5 . He is tall and very good-looking.

6. My sister's hair is medium length.

7. I have dark brown eyes.

Example 23 (p. 26, “focus on meaning”) Grammar Focus.

B. Response to three invitations. Then write three invitations to the given responses.

1. A. I have tickets to the baseball game on Saturday. Would you like to go? B.

2. A. Would you like to come over for dinner tomorrow night?

B.

3. A. Would you like to go to a pop concert with me this weekend?

B.

4. A.

B. Yes, I would love to. Thank you!

5. A.

B. Well, I would like to, but I have to study.

6. A.

B. Yes, thank you. I would really like to see it.

Example 24 (p. 27, “focus on meaning”) Reading.

A. Read the article. Then number these statements from “1” (First event) to "8” (Last event).

a. She sings at the Winter Olympic Games.

b. She is born in New York

c. She wins a Grammy for "beautiful."

d. She records a song for a Disney movie.

e. She travels around Japan.

f. She works with Britney Spears.

g. She is on television for the first time.

h. She has her first very successful song.

Examples 22, 23, and 24 can be argued that they fall into "information-gap activities.” The author does not ignore this argument, but within the analysis, these three examples, which are representatives of "focus on meaning," are classified as "focus on meaning." In these three different tasks, students mainly base their answers on the meanings themselves rather than grammar forms, as in Examples 22 and 23.

Out of the 10, there are some remaining activities that are pronunciation and self-assessment with roughly $1 \%$ and $2 \%$, respectively. These are the sub-headings themselves, which appear in the textbook, because they cannot be allocated to the 10 chosen characteristics. Moreover, they cannot categorise into other characteristics 
discussed in the literature either. Therefore, they are left as what they are in the textbook. Examples of pronunciation and self-assessment are shown below.

Example 25 (p. 62, “pronunciation”)

\section{PRONUNCIATION Contrastive stress in responses}

A (1) Listen and practice. Notice how the stress changes to emphasize a contrast.

A: Is Anthony the one wearing the red shirt? A: Is Judy the woman on the couch?

B: No, he's the one wearing the black shirt. B: No, Diana is the woman on the couch.

B Mark the stress changes in these conversations. Listen and check. Then practice the conversations.
A: Is Britney the one sitting next to Katy?
A: Is Donald the one on the couch?
B: No, she's the one standing next to Katy.
B: No, he's the one behind the couch.

Example 26 (p. 70, “self-assessment”)

\section{SELF-ASSESSMENT}

How well can you do these things? Check $(\checkmark)$ the boxes,

I can.... Very well OK A little

Ask about and describe people's appearance (Ex. 1)

Identify people using modifiers with participles and prepositions (Ex. 2)

Answer questions using the present perfect with already and yet (Ex. 3)

Listen to and understand descriptions of past experiences and events $\langle$ Ex. 4)

Ask and answer questions using the present perfect and simple past (Ex. 4)

Use how long, for, and since with the present perfect (Ex. 5)

Example 27 (p. 84, “self-assessment”)

\section{SELF-ASSESSMENT}

How well can you do these things? Check $(\checkmark)$ the boxes.

\begin{tabular}{l}
\hline can.... Very well \\
\hline Listen to and understand descriptions of cities $($ Ex. 1) \\
Describe places using adjectives, adverbs, and conjunctions (Ex. 1, 2) \\
Ask questions about cities and hometowns (Ex. 2) \\
Ask for and give suggestions with can and should (Ex. 2, 3) \\
Ask for and give advice using infinitive complements (Ex. 3, 4) \\
Give suggestions on a variety of problems (Ex. 4)
\end{tabular}

\section{Discussion}

According to the results presented above, the textbook—New Interchange 1 -seems to favour with the 
"information-gap” and "opinion-sharing activities.” On the contrary, less focus is given to "reasoning-gap” and "thinking skills." The results showed that Richards, Hull, and Proctor (2005), the main author of the analysed textbook, put the main focus on his own communicative language teaching characteristics, "information-gap" and "opinion-sharing activities." As it can be seen from the results, "information-gap activities” occur $17 \%$ and "opinion-sharing" appears $15 \%$ of the time. However, it is surprising to note that his third category_- "reasoning-gap," chosen for analysis falls far behind the two dominating activities in the textbook, with $5 \%$ of the time only.

On the other hand, Richards, Hull, and Proctor (2005) used mixed activities within principle theories of communicative language teaching throughout the analysed textbook. They also valued the theories of other writers of CLT, such as Dornyei (2009), Jacobs and Farrell (2003), and Jin (2012) in addition to their main focuses, "information-gap” and "opinion-sharing activities," from their own characteristics. Of the three writers and following the two dominating activities, the textbook also prioritised Jin's (2012) suggestions of "ask and answer dialogue," "situational dialogue," and also "communicative dialogue.” Richards et al. (2005) also used the "focus on form" to illustrate some of grammar points in every unit of the textbook. Nonetheless, the forms that are focused in the textbook are not explicit but rather just simple brief explanation.

Presenting those main focuses upon the characteristics above does not mean that the textbook ignores other weight of communicative language teaching. It also employs other communicative principles, such as "learner autonomy," "focus on meaning," and "thinking skills” in which Jacobs and Farrell (2003) suggested, which contribute to communicative competence to produce confident communicators throughout the textbook and the course of IEAP at PUC-SR.

However, within the analysis, some activities can be argued or overlapped among the 10 principles. Therefore, the results can lead to different findings if different analysts re-examine the same textbook. Nevertheless, there must not be very much different in terms of communicative activities or CLT in general. As a case of "situational dialogue" and "communicative dialogue," some activities can be categorised as both. However, they are only analysed once to avoid repetition of activities and either of them is communicative activity.

Communicative textbooks do not mean that the teaching of English using CLT is always successful. Other contributing factors become necessary when textbooks are used in practical classrooms. Those include supporting documents (teaching outlines), teachers, additional resources, and students as well. By briefly inspecting the teaching syllabus outlining contents of the textbook analysed to be used in the classrooms, it does not provide enough detail or what should be supplemented to any of those that may not be communicative. Besides brief summary of the textbook, which allocates activities within specific timeframe, the outline provides assessment guidelines for the course, which is good. However, the tests are not analysed so further comments cannot be made if those tests are communicative or not.

A primary contributor to the communicative classrooms is a teacher himself/herself, who facilitates the communicative language learning. A textbook is only as good as the way the teacher uses it. It can be used communicatively or not. A textbook might be used in a very dry, grammar-translation style, and the communicative aspect could be lost. Cambodian teachers in general have much favour with traditional teaching approach and grammar-translation method. And their current implementation of CLT in their classrooms is somewhat considerate. Many teachers continue to have strong beliefs that students are required to acquire the accurate grammar structures and translation from and to the mother tongue, so that students can use the target language accurately. Therefore, how and how much teachers utilise CLT in their classrooms is still unknown. 
According to Wei (2011), EFL countries should study their English teaching situations and decide how CLT can serve their needs and interests. In addition, Wei (2011) raised challenges perceived by EFL teachers in adopting CLT, particularly the predominance of traditional teaching method and teacher-centred approach. Therefore, student-centred, fluency-focused, and problem-solving activities are not easily implemented in these traditional teaching contexts in Southeast Asian countries, such as Cambodia (Li, 1998, as cited in Wei, 2011).

In a similar context, in introducing CLT approach in China, Liao (2000) asserted that teachers believed CLT adoption was not feasible because of Chinese special characteristics including teachers' inability to teach communicatively and grammar-focused examination pressure. However, a report of an experimental study on the importance of introducing the communicative approach in Pakistan. ELT in teacher training programmes shows that CLT enhances learners' confidence and it gives a sense of satisfaction to the teachers in a sense that teachers are successful in making students use the foreign language in their conversation (Akram \& Mehmood, 2011).

Another necessary contributing factor to communicative teaching and learning can also be seen additional resources. Using textbooks alone in classrooms is boring even if communicative textbooks as New Interchange 1 , so students may lead demotivated. As it can be seen that all over the analysed textbook and the same as other textbooks in terms of structures and organisations, from one unit to another components/sub-headings appear the same. At this stage, choosing/integrating good additional resources becomes attractive/interesting, so that students are eager to learn and never tired.

However, additional materials/resources that teachers use in their classroom need to be authentic. For example, Chan (2013) studied the role of situational authenticity in English language textbooks in Hong Kong. His analysis involves the qualification and categorisation of both written and spoken texts in the textbooks. The results of his analysis are compared with empirical evidence about Hong Kong people's real-life language use. The findings reveal that a close alignment between the language-using contexts in textbooks and the real world is unrealistic, inappropriate, and virtually impossible at school. Two interesting of challenges in his study are local educational constraints and the lack of need analysis of the local language-using contexts for textbook design.

Despites those factors mentioned above, students play important role to contribute the success of CLT in Cambodian EFL contexts. Although English is required by many jobs in Cambodia and is a language of instruction in all academic disciplines at PUC-SR, motivation of students who are participating the IEAP programme is never explored. Therefore, how students perceive CLT or how much they participate in the CLT activities is yet unknown. Based on observations, some students come to school just to fulfil their parents' demands rather than their own motivation. Also, Cambodia is an EFL context, so students find it hard to practice or use English outside their classrooms.

In addition to the four factors discussed above, inter-cultural contents within the textbook itself are crucially important. As in an analysis of a local produced textbook in Bangladesh, in which Siddiqui (2011) aimed to examine the proportion and kinds of inter-cultural contents in English language textbook-English for Today, and investigated inter-cultural awareness and abilities promote in the textbook. Siddiqui (2011) found that inter-cultural contents that used in the textbook were interesting and fruitful to Bangladeshi learners. These inter-cultural contents have opened new possibilities to contribute to learners' awareness about the world around them. Finally, Siddiqui (2011) concluded that the findings would help students develop a sense of global citizenship and compare and contrast their own country and culture from a global perspective. 


\section{Conclusions}

It can be seen that almost every piece of the activities within the analysed textbook fall into the ten characteristics of communicative language teaching principles that are suggested by Dornyei (2009), Jacobs and Farrell (2003), Jin (2012), and Richards (2006). However, every characteristic, among the 10 activities chosen, does not have the same number of occurrences, which occurs throughout the textbook. This is not strange, because the focus of skills from one level to another is usually different. Beginner level should focus on foundation of communicative skills, such as "ask and answer dialogue," "situational dialogue," and "communicative dialogue." "Learner autonomy” and "thinking skills” may become increase while students are progressing to higher levels of English proficiency. However, the scope and time limitations of the dissertation timeline require the limitation of this study to one textbook level.

In short, it means to say that the analysed textbook is highly communicative according the findings released although some activities cannot be categorised into those selected characteristics of CLT. However, there are not many of them within the textbook. In addition, all activities that fall into the 10 categories are all communicative activities although they are not allocated equally. As the results show, this textbook is a very communicative textbook for such the programme to build students' foundations of communication skills, so that they become ready and more independent for their academic endeavour later in the university, where English is the only medium language of instruction in all disciplines.

However, this cannot be guaranteed that PUC-SR's IEAP programme becomes very successful in teaching English communicatively, because other factors contributing CLT's implementation have not been explored. Hence, the results only release the chosen textbook alone, which is being analysed, not a successful CLT case at PUC-SR for the IEAP programme as a whole. Those contributing factors, as concerned discussions being made above, may include but not limit to teaching outlines, teachers, additional resources, students, and inter-cultural contents within the textbook.

\section{Recommendations}

Although the textbook is very communicative based on the results reported, there are still other factors can contribute to successful effective communication. Those include students, teachers, curriculum designers, and institutions themselves, which can contribute to successful implementation of CLT in Cambodian EFL contexts in general and at PUC-SR in particular.

First of all, students should continuously be encouraged to attend classrooms regularly in the English language programme in general and in particular in this low level of English. Also, they should participate actively in any activities set to gain the most communicative foundations, so that learners can become successful communicators later at higher levels and in their academic programmes.

Additionally, teachers should continuously improve their language proficiency in general as Brown (2007) suggested that some characteristics might make it difficult for a non-native speaking teacher whose proficiency was limited to teach second language communicatively and they should particularly improve the contemporary teaching methodology_CLT approach. As a result of their continuous improvements, they should be able to use/create supplementary materials when necessary or where they find that activities in the textbook may not be communicative without too much difficulty. Therefore, they may not solely base on the prescribed textbook and designed teaching outlines/curriculum, or they become flexible to ensure communicative classrooms. 
Besides the two factors discussed above contributing to effectively communicative teaching, curriculum designers should design teaching syllabi communicatively. This may include suggestion for supplementary materials where suitable to add to existing activities throughout the textbook. Also, they should propose a teachers' professional development programme on a basis of specific time to train techniques/skills of the teaching for effective communication to the current and future teachers.

According to Igawa and Tsujioka (2009), Cambodian, Japanese, and Korean teachers were much interested in three, out of 10, significant areas of professional development (PD), such as teaching skills and methods, language improvement, and understanding students, the most preferable of which was teaching skills and methods. This reflects that the lack of communicative teaching skills and methods is more critical than the later two in implementing CLT among Cambodian, Japanese, and Korean teachers. Therefore, quality professional development should be ensured, so that English teachers are able to acquire mastery of curricular content knowledge or putting it into practice pedagogically pertinent to teaching practices.

To achieve quality training, Miller and Aldred (2000) suggested that teacher education programmes included the process of discussion, evaluation, and reflection in the training course, through which the teacher trainees can build a sense of collaborative learning when attending the training programs. The researchers also maintain that such areas of focus should not be seen as an adjunct to such courses but an integral part of them (p. 17). Additionally, Ustunluoglu (2009) recommended the inclusion of the concept of learning autonomy in curriculum by incorporating a well-structured focus, delivery, and content, so that teachers can follow to move their students towards autonomous learning.

Last but not least, institutions play important roles to provide a primary communicative environment. Classrooms and learning resource centres should be well and resourcefully equipped. When facilities become available on campus, teachers and students have convenient access and use, so that they only focus on their tasks. Therefore, their attention becomes full and ready for those communicative activities without too much difficulty.

However, further research should be explored in order to find out effectiveness of CLT within the IEAP programme as a whole into relevant fields, such as effectiveness of textbooks, analysis of the remaining textbooks, implementation and effectiveness of CLT, students' and teachers' perceptions, and attitudes toward CLT, and challenges of CLT in Cambodian higher education in general and at PUC-SR in particular.

\section{References}

Akram, M., \& Mehmood, A. (2011). The need of communicative approach (in ELT) in teacher training program in Pakistan. Language in India, 11(5), 172-178.

Brown, H. D. (2007). Teaching by principles: An interactive approach to language pedagogy (5th ed.). New York: Pearson ESL. Byram, M. (1997). Teaching and assessing intercultural communicative competence. Clevedon: Multilingual Matters.

Byram, M., \& Risager, K. (1999). Language teachers, politics, and cultures. Clevedon: Multilingual Matters.

Carreres, A., \& Noriega-Sanchez, M. (2011). Translation in language teaching: Insights from professional translator training. The Language Learning Journal, 39(3), 281-297.

Chamnan, P., \& Ford, D. (2004). Cambodian higher education: Mixed visions. In P. G. Altbach, \& T. Umakoshi (Eds.), Asian universities: Historical perspectives and contemporary challenges (pp. 333-362). Baltimore: Johns Hopkins University Press.

Chan, J. Y. H. (2013). The role of situational authenticity in English language textbook. RELC Journal, 44(3), 303-317.

Chen, S. (2009). Intercultural team teaching: A study of local and foreign EFL teachers in Taiwan (Unpublished doctoral dissertation, Durham University, Durham, UK).

Chowdhry, M. R. (2010). International TESOL training and EFL contexts. Retrieved October 7, 2014 from http://alwaysingreen.blogspot.com/2010/12/International-tesol-training-and-efl.html 
Chu, H. C., Swaffar, J., \& Charney, D. (2002). Cultural representations of rhetorical conventions: The effects on reading recall. TESOL Quarterly, 36, 511-538.

Corbin, J., \& Strauss, A. (2008). Basics of qualitative research: Techniques and procedures for developing grounded theory (3rd ed.). Thousand Oaks, C.A.: Sage.

Dornyei, Z. (2009). The 2010's communicative language teaching in the 21st century: The principled communicative approach. Perspectives, 36(2), 33-43.

Ellis, R. (2000). Task-based research and language pedagogy. Language Teaching Research, 4(30), 193-220.

Fereday, J., \& Muir-Cochrane, E. (2006). Demonstrating rigor using thematic analysis: A hybrid approach of inductive and deductive coding and theme development. International Journal of Qualitative Methods, 5(1), 80-92.

Hird, B. (1995). How communicative can English language teaching be in China? Prospect, 10(3), 21-27.

Holliday, A. (1995). Handing over the project: An exercise in restraint. System, 23, 57-68.

Holliday, A. (1999). Small cultures. Applied Linguistics, 20, 237-264.

Hu, G. (2002). Potential cultural resistance to pedagogical imports: The case of communicative language teaching in China. Language, Culture, and Curriculum, 15, 93-107.

Hu, G. (2005). CLT is best for China—An untenable absolutist claim. ELT Journal, 59(1), 65-68.

Igawa, K., \& Tsujioka, N. (2009). Professional development needs of Cambodian teachers of English: International comparison with Japanese and Korean EFL teachers. CamTESOL Conference on English Language Teaching, 5, 88-98.

Jacobs, G., \& Farrell, T. S. C. (2003). Understanding and implementing the CLT (Communicative language teaching) paradigm. RELC Journal, 34(1), 5-30.

Jin, Y. (2012). On the cultivation of oral English communicative competence in teaching. International Journal of English Linguistics, 2(3), 59-63.

Kelly, M., Elliott, I., \& Fant, L. (2001). Third level, third space: Intercultural communication and language in European higher education. Bern: Peter Lang.

Kramsch, C. (1999). Thirdness: The intercultural stance. In T. Vestergaard (Ed.), Language, culture, and identity (pp. 41-58). Aalborg: Aalborg University Press.

Kramsch, C. (2004). Language, thought, and culture. In A. Davies, \& C. Elder (Eds.), The handbook of applied linguistics (pp. 235-261). Oxford: Blackwell.

Lai, C., Zhao, Y., \& Wang, J. (2011). Task-based language teaching in online Ab Initio foreign language classroom. The Modern Language Journal, 95, 81-103.

Lazaraton, A. (2003). Incidental displays of cultural knowledge in the non-native-English-speaking teacher's classroom. TESOL Quarterly, 37, 213-245.

Leng, P. (2010). Students' perceptions towards private higher education sector in Cambodia (Unpublished M.A. thesis, Ohio University).

Li, S., \& Li, F. (2004). Intercultural communicative language teaching: Rethinking the communicative approach to ELT in China. Harbin Institute of Technology PR ea journal, 22(1), 1-24.

Liao, X. Q. (2000). How CLT became acceptable in secondary schools in China? Retrieved October 7, 2014 from http://iteslj.org/Articles/Liao-CLTinChina.html

Mak, N. (2005). A current update of higher education in South-East Asian countries: The case of Cambodia. Bangkok: Thailand.

Miller, L., \& Aldred, D. (2000). Student teachers’ perceptions about communicative language teaching methods. RELC Journal, 31(1), 1-22.

MoEYS. (2007). Prakas No 1435 MoEYS. PK on conditions and the details for licensing higher education institution. Phnom Penh: MoEYS.

MoEYS. (2013). The statistics degrees and courses offered by higher education institutions. Phnom Penh: Department of Higher Education.

Neau, V. (2010). The teaching of foreign languages in Cambodia: A historical perspective. Language, Culture, and Curriculum, 16(3), 253-268.

Prabhu, N. S. (1987). Second language pedagogy. Britain: Oxford University Press. Retrieved October 8, 2014, from http://onlinebooks.library.upenn.edu/webbin/book/lookupid?key=olbp46039

Ramanathan, V. (1999). English is here to stay: A critical look at institutional and educational practices in India. TESOL Quarterly, 33(2), 211-231.

Richards, J. C. (2006). Communicative language teaching today (3rd ed.). New York: Cambridge University Press. 
Richards, J. C., Hull, J., \& Proctor, S. (2005). New interchange student’s book 1 (3rd ed.). Cambridge: Cambridge University Press.

Risager, K. (2006). Language and culture: Global flows and local complexity. Clevedon: Multilingual Matters.

Siddiqui, S. A. (2011). Intercultural exposure through English language teaching: An analysis of English language textbook in Bangladesh. Pan-Pacific Association of Applied Linguistics, 15(2), 109-127.

Silverman, D. (2000). Doing qualitative research: A practical handbook. Thousand Oaks, C.A.: Sage.

Strauss, A., \& Corbin, J. (1998). Basics of qualitative research: Techniques and procedures for developing grounded theory (3rd ed.). New York: SAGE Publications, Inc..

Tong, D. M. (1999). Sequencing and grading in task-based syllabus design: The state of the art. Available from ERIC database (ED 440 553).

Ustunluoglu, E. (2009). Autonomy in language learning: Do students take responsibility for their learning? Journal of Theory and Practice in Education, 5(2), 148-169.

Van Ek, J. (1986). Objectives for foreign language learning (Vol. 1: Scope). Strasbourg: Council of Europe.

Van Ek, J., \& Trim, J. L. (1991). Threshold level 1990. Strasbourg: Council of Europe.

Vasilopoulos, G. (2008). Adapting communicative language instruction in Korean universities. The Internet TESOL Journal, 14(8).

Wei, L. (2011). CLT in EFL context: Not a universal medicine. IDIOM, 41(3).

Wenjie, C. (2009). Using CLT to improve speaking ability of Chinese non-English major students (M.A. thesis, University of Wisconsin Platteville). Retrieved October 8, 2014, from http://minds.wisconsin.edu/handle/1793/34646?show=full

Yin, R. K. (2003). Case study research: Design and methods. Thousand Oaks, Calif: Sage Publications.

Young, T. J., \& Sercombe, P. (2010). Communication, discourses, and interculturality. Language and Intercultural Communication, 10, 181-188.

Young, T., Sachdev, I. (2011). Intercultural communicative competence: Exploring English language teachers' beliefs and practices. Language Awareness, 20(2), 81-98. DOI: 10.1080/09658416.2010.540328

Young, T. J., Sachdev, I., \& Seedhouse, P. (2009). Teaching and learning culture on English language programmes: A critical review of the recent empirical literature. Innovation in Language Learning and Teaching, 3, 149-169. 